\title{
Educação e hegemonia camponesa: MST e educação do campo no estado do Ceará
}

Pedro Claesen Dutra Silva

Mestrando em Educação pela Universidade Federal do Ceará

\section{Resumo}

O estudo desenvolvido procura demonstrar como a Educação do Campo, cujo processo de elaboração teórico-prática, vem sendo protagonizado pelo Movimento dos Trabalhadores Rurais (MST) em todo o Brasil, pode contribuir decisivamente para a construção de uma nova hegemonia. Assim, iniciando o texto com uma conceituação teórica dessa perspectiva pedagógica, passando posteriormente por uma revisão bibliográfica sobre o tema e o pensamento do pensador italiano Antônio Gramsci, procurar-se-á problematizar os principais desafios postos à materialização da Educação do Campo a partir da realidade do estado do Ceará.

Palavras-chave: Educação do Campo; MST; Hegemonia.

\section{Resumen}

El estudio desarrollado procura demostrar como la educación del campo, cuyo proceso de elaboración teórico-práctica, viene siendo protagonizada por el movimiento de los trabajadores rurales (MST) en todo el Brasil, puede contribuir decisivamente para la conceptualización teórica de una nueva hegemonía. Así, iniciando el texto con una conceptualización teórica de esa perspectiva pedagógica pasando posteriormente por una revisión bibliográfica sobre el tema y el pensamiento del pensador italiano Antonio Gramsci, se procura problematizar los principales desafíos puestos en la materialización de la educación del campo a partir de la realidad del estado de Ceará.

Palabras clave: Educación del Campo; MST; Hegemonía. 


\section{Introdução: conceituando a educação do campo}

Educação do Campo possui influências diretas de três matrizes
pedagógicas vinculadas ao pensamento crítico e aos objetivos
políticos de emancipação e de luta das classes subalternas. Neste sentido, este estudo foi desenvolvido com a intenção de apresentar elementos que demonstrem a perspectiva da Educação do Campo em contribuir com a construção de uma nova hegemonia, processo que tem o Movimento dos Trabalhadores Rurais Sem Terra (MST) como o principal sujeito.

A primeira das matrizes é a tradição do Pensamento Pedagógico Socialista, que nos ajuda a pensar a relação entre educação e produção, bem como a dimensão pedagógica do trabalho e da organização coletiva. Pois, a partir do conceito de trabalho (da atividade teórico-prática) se fornece o ponto de partida para o posterior desenvolvimento de uma concepção histórico-dialética do mundo, para a compreensão do movimento e do devenir, para a valorização da soma de esforços e de sacrifícios que o presente custou ao passado e que o futuro custa ao presente, para a concepção da atualidade como síntese do passado, de todas as gerações passadas, que se projeta no futuro (GRAMSCI, 1988).

A segunda referência para essa interlocução é a Pedagogia do Oprimido e toda a tradição pedagógica decorrente das experiências da Educação Popular, que incluem o diálogo com as matrizes pedagógicas da opressão (a dimensão educativa da própria condição de oprimido) e da cultura (a cultura como formadora do ser humano). Segundo Freire (2005):

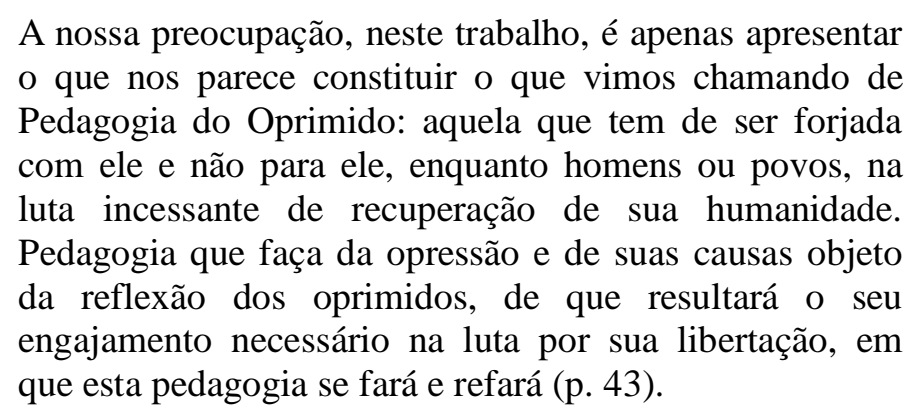

A terceira matriz vem de uma reflexão teórica mais recente, 
denominada de Pedagogia do Movimento, que também dialoga com as tradições anteriores, mas que se produz desde as experiências educativas dos próprios movimentos sociais, em especial dos movimentos sociais do campo. Trata-se de pensar e olhar o movimento social como sujeito pedagógico e a luta enquanto princípio educativo, pondo em movimento a própria pedagogia, mobilizando e incorporando em sua dinâmica (organicidade) diversas e combinadas matrizes pedagógicas (CALDART, 2004).

Dessa forma, a Educação do Campo fundamenta-se numa concepção de educação no sentido amplo do processo de formação humana, que constrói referências culturais e políticas para a intervenção dos sujeitos sociais na realidade.

Nessa pesquisa, partimos da compreensão de que a educação está inserida em um processo permanente de disputas e interesses antagônicos, característicos da própria sociedade dividida em classes. Leher (2005) sinaliza que as classes dominantes tem sido vitoriosas neste terreno de disputa, o que torna ainda mais urgente o compromisso ético-político de pesquisadores no desenvolvimento de reflexões que contribuam com o desenvolvimento de processos educativos emancipatórios, vejamos:

Como a educação está imersa nas contradições da sociedade de classe, a sociedade realmente existente, a difusão de que a educação é neutra não se coaduna com a realidade. $O$ seu entrelaçamento com a luta de classes não é apenas uma "triste imperfeição" da história, pois a luta de classes é um instrumento até o presente, necessário para o desenvolvimento social. A predominância das concepções tecnicista, romântica e pós-moderna expressa, por conseguinte, a força relativa das classes dominantes que têm logrado impor o seu modo de pensar a Educação (p. 21).

\section{O PRONERA no Brasil e no Ceará}

Ao tratarmos da Educação do Campo, não podemos deixar de destacar o Programa Nacional de Educação na Reforma Agrária (PRONERA), pois este programa tem contribuído na luta dos movimentos 
sociais do campo em se aproximar das universidades públicas brasileiras e na garantia do direito à educação em todos os níveis aos trabalhares(as) rurais em todo o país há mais de uma década, assim como, ao protagonismo do Movimento dos Trabalhadores Rurais Sem Terra (MST), que tem sido um sujeito efetivo e atuante em todo esse processo. O PRONERA foi criado no seio das lutas pela Educação do Campo e exprime uma demanda de ações educativas concretas em áreas de Reforma Agrária.

É importante ressaltar que os piores índices educacionais brasileiros encontram-se no campo, onde vivem mais de 30 milhões de brasileiros. A taxa de analfabetismo entre os adultos nas áreas rurais é de 29,8\% e apenas $23 \%$ dos alunos de 10 a 14 anos estão na série adequada a sua idade. No meio rural a distorção idade/série das crianças do $1^{\circ}$ segmento do ensino fundamental ( $1^{\text {a a }} 5^{\text {a }}$ série) é de $39,4 \%$, enquanto nas áreas urbanas é de $18,5 \%$, com dados ainda piores nos segmentos seguintes do ensino fundamental e médio, segundo dados do próprio MST existem hoje 2 mil escolas públicas em assentamentos e acampamentos, destas apenas 50 tem o ensino médio completo.

Todavia, pode-se afirmar que devido a força dos movimentos sociais na luta em defesa da Educação do Campo, em especial ao MST, tem-se ampliado o direito à educação ao povo camponês, principalmente em torno do PRONERA. Hoje, em parcerias e convênios com dezenas de universidades públicas em todo o país, milhares de trabalhadores(as) rurais estão tendo acesso a inúmeros projetos educacionais, desde a alfabetização de jovens e adultos à pós-graduação.

Para compreendermos com mais clareza como tem se dado esse avanço, selecionamos alguns dados relevantes: 1 . mais de 200 mil crianças e adolescentes Sem Terra estão estudando, cerca de 95\% a partir de um currículo especial para jovens do campo; 2. mais de 250 cirandas infantis (espaço para educação de crianças entre 0 e 6 anos) funcionam junto às cooperativas e associações de produção nos assentamentos, acampamentos e cursos de formação; 3. são 45 escolas itinerantes (escolas que adam juntas dos acampamentos), com mais de 350 educadores(as) do movimento e cerca 
de 4 mil alunos; 4. o MST tem parceria com mais de 50 instituições de ensino, entre universidades e escolas técnicas. São aproximadamente 100 turmas de cursos formais, num total de 4 mil estudantes jovens e adultos e 5 . mais de 100 mil pessoas aprenderam a ler e escrever no MST, sendo formados mais de 4 mil professores ${ }^{1}$.

Alguns marcos históricos são importantes na trajetória da Educação do Campo em âmbito nacional, dentre eles: a I Conferência Nacional por uma Educação Básica do Campo e a criação do Programa Nacional de Educação na Reforma Agrária (PRONERA) ${ }^{2}$ em 1998; a aprovação das Diretrizes Operacionais para Educação Básica nas Escolas do $\mathrm{Campo}^{3}$ em 2002 e a realização do III Seminário Nacional do Programa Nacional de Educação na Reforma Agrária em $2007^{4}$.

No estado do Ceará, destacamos a construção de parcerias entre o MST e a Universidade Federal do Ceará (UFC) em torno do Curso Pedagogia da Terra entre 2004 e 2008, que formou 80 educadores(as) para lecionarem em áreas de reforma agrária em todo o estado, bem como com a Universidade Estadual do Ceará (UECE), através do desenvolvimento dos projetos de Escolarização de Trabalhadores e Trabalhadoras Rurais no I Segmento do Ensino Fundamental que proporcionou a formação de 110 educadores(as) de educação de jovens e adultos, evolvendo cerca de 2.400 educandos em 120 salas de aula entre os anos de 2006 e 2008 e o Curso de Formação de Educadores e Educadoras de Assentamentos Rurais em Áreas de Reforma Agrária - Magistério da Terra, que formou 107 (cento e sete) educadores(as), em nível médio, com habilitação para o magistério em educação infantil e séries iniciais do ensino fundamental, que teve início em

\footnotetext{
${ }^{1}$ Fonte: Jornal dos trabalhadores rurais Sem Terra. Número 294 - Julho de 2009.

${ }^{2}$ Em 6 de abril de 1998, por meio da Portaria $n^{\circ}$ 10/98 foi criado o Programa Nacional de Educação na Reforma Agrária - PRONERA, então vinculado ao Gabinete do Ministro Extraordinário da Política Fundiária.

${ }^{3}$ Parecer n ${ }^{0}$ 36/2001 e Resolução 1/2002 do Conselho Nacional de Educação.

${ }^{4}$ Realizado entre os dias 2 a 5 de outubro de 2007 na cidade de Luiziana - Goiás, no qual tive a oportunidade de participar enquanto delegado.
} 
2006 e foi concluído em 2010.

Carvalho (2006), nos ajuda a compreender como se constroem as parcerias entre o MST e as universidades:

A construção da parceria mostra-se processual, para aquém ou além da assinatura de convênios. Quando os movimentos buscam as universidades, já procuram mediadores como professores ou alunos com quem têm vínculos de confiança para elaboração dos projetos; após a aprovação e ao firmarem-se os contratos de trabalhos a relação com novas instituições ainda estarão por ser construídas. Ao identificar-se protagonistas aliados e antagonistas, dá-se interrelações contraditórias que também são flutuantes, ou seja, em determinados momentos podem os aliados tornarem-se antagônicos (p. 161 e 162).

Nesse diálogo, entre os movimentos sociais do campo e as universidades públicas brasileiras, no caso específico entre o MST, a UECE e a UFC, uma característica tem sido intrínseca e permanente: o conflito. O conservadorismo, ainda muito presente no meio acadêmico, custa aceitar que camponeses Sem Terra tenham acesso à universidade, direta ou indiretamente.

\section{Educação do campo e hegemonia camponesa}

Através de informações dadas pelo membro do setor de educação do MST e a partir da análise de textos e documentos produzidos pelo Movimento, percebemos com mais clareza como o projeto políticoeducacional da Educação do Campo se materializa, levando em consideração as contradições postas na realidade e a relação conflituosa entre sociedade civil e Estado.

Para o desenvolvimento de uma atividade educacional se proponha contribuir para uma hegemonia de novo tipo, duas condições são necessárias: a) a relação da proposta educativa com os processos de organização autônoma das classes subalternas; e b) a dimensão do diálogo e da práxis enquanto processos de conscientização e transformação da realidade material dos sujeitos envolvidos. Dessa forma, procuramos 
compreender como o MST se vincula a esses dois pontos, analisando as concepções e paradigmas que orientam suas ações, projetos e iniciativas desenvolvidas.

Como temos observado, a Educação do Campo tem relação direta com a luta pela democratização da terra. Logo, as experiências educacionais desenvolvidas estão essencialmente vinculadas a um projeto alternativo do campo brasileiro, antagônico ao modelo sustentado pela hegemonia da agricultura empresarial, o agronegócio.

Para compreendermos como se dão os processos de tomada de consciência dos sujeitos envolvidos, assim como os conflitos constantes na relação entre movimento social e Estado, a passagem abaixo é bem elucidativa:

Temos levado esses programas [governamentais] para dentro do Movimento, pra dinâmica do Movimento, introduzindo o Movimento dentro da sala de aula, ou seja, além do processo propriamente dito do estudo mais sistematizado do conhecimento. Nós temos introduzido o jeito do Movimento, com as místicas, com a própria consciência de classe, trabalhadas de diferentes formas, seja nas reflexões teóricas como na prática do cotidiano, na luta de resistência contra o sistema capitalista. De repente estamos no curso e deu algum problema, não só na liberação de recursos como em algum entrave político ou ideológico que o Estado acaba colocando nas atividades dos projetos, a gente ocupa [prédios públicos, como o INCRA ou as reitorias das universidades], enfim, esse é o jeito do Movimento ser e nós damos os rumos, na verdade nós coordenamos o processo, o Estado participa, mas o protagonismo é dos sujeitos envolvidos no processo (Membro do MST).

Podemos observar que apesar da parceria com o poder público, seja em âmbito nacional ou estadual, o MST procura manter sua autonomia durante o desenvolvimento de projetos e programas. Em momentos de acirramento do conflito "entre as partes", o Movimento chega a lançar mão, de uma de suas principais táticas de luta, a ocupação, com o intuito de agilizar a liberação dos recursos destinados aos projetos do Programa Nacional de Educação na Reforma Agrária (PRONERA).

A dimensão do diálogo, na Educação do Campo, vincula-se à 
construção de uma identidade de classe, o ser Sem Terra. O forjamento dessa identidade está fundamentalmente relacionado com uma práxis revolucionária, em que o ser humano é pensado em relação permanente e dialética com o mundo, a partir de seus condicionamentos e desafios, para que o oprimido rompa com sua situação de desumanização e assuma sua condição ontológica de ser mais ${ }^{5}$.

Pra nós todo movimento que luta e transforma o ser e o meio em que vive, deve utilizar-se do diálogo, na perspectiva do encontro entre as pessoas, e da Pedagogia do Movimento. Mas trazendo pra nós mesmos, a Pedagogia do Movimento no MST e essa dimensão do diálogo, tem sido o jeito pelo qual o Movimento vem forjando o novo ser, um ser de nome Sem Terra [...] diferenciando o sem terra da condição social do Sem Terra vinculado a uma identidade. O ser sem terra minúsculo é relacionado à condição social o ser Sem Terra maiúsculo seria aquele que mesmo tendo conquistado sua terra, ele é um novo ser que luta pela transformação da sociedade, que tem outros valores, que em sua prática cotidiana se indigna com as injustiças e que tem sede de lutar, então é aquele que diz: Sou Sem Terra! Essa pedagogia e esse diálogo têm produzido esse ser Sem Terra que inclusive tem uma nova consciência e busca permanentemente o conhecimento (Membro do MST).

Deste modo, uma atividade educativa ou uma ação pedagógica que pretenda contribuir para uma formação integral e emancipatória do ser humano terá que buscar permitir aos indivíduos engajar-se na luta pela construção de uma sociabilidade para além do capital. Assim, percebe-se que a educação tem um papel central no estabelecimento da hegemonia em determinada sociedade. É ilustrativo, por exemplo, a preocupação de Gramsci com a formação da juventude italiana pelo Estado fascista:

A discussão de Gramsci sobre a educação da sobrinha continuará, de outra forma, quando Mea for estudar na escola pré-profissional. Esse tio comunista, encarcerado, conhece bem a realidade social e escolar italiana e, mais ainda, a de sua região, a Sardenha. É uma realidade de gostaria de mudar e que, no entanto, política e

\footnotetext{
${ }^{5}$ Para Freire (2005), ser mais seria “Uma vocação negada na injustiça, na exploração, na opressão, na violência dos opressores. Mas afirmada no anseio de liberdade, de justiça, de luta dos oprimidos, pela recuperação de sua humanidade roubada” (p. 30).
} 
ideologicamente, está cada vez mais influenciada e "educada" por um estado fascista. [...] Teme, Gramsci, que o clima educativo cultural, produzido por Mussolini e seu partido, consiga desviar a juventude dos ideais socialistas (NOSELLA, 2004. p. 130).

As iniciativas e reflexões levantadas pelo MST a partir da luta pela Educação do Campo, contrapõem-se a hegemonia dirigida pela classe dominante. Nesse sentido, o MST tem a preocupação em forjar uma nova hegemonia que aponte para o fortalecimento e robustecimento da sociedade civil, em que os processos educativos (formais e/ou informais), assumem um papel central em sua estratégia. Enfim, apontando para uma nova direção moral e cultural do povo camponês.

\section{A escola da educação do campo}

Uma questão importante relacionada com a estratégia do MST está no debate sobre o sistema escolar propriamente dito. Ao espaço, a organização, aos parâmetros curriculares e a formação dos educadores (as) das escolas, principalmente aquelas localizadas no interior dos assentamentos rurais. Dessa forma, procura-se construir uma espécie de “escola pública popular", ou simplesmente, a "escola do campo". Atualmente existe um quase vazio em relação a propostas pedagógicas que tomem o campo como referência, no próprio âmbito das teorias educacionais críticas, o parâmetro é o das escolas urbanas (uma perspectiva urbanocêntrica de escola). Para o MST:

Todo o conjunto da escola deve ser assumida pela própria comunidade, onde o poder público vai interferir apenas naquilo que lhe compete, mas não acontecendo como costumeiramente tem sido feito, em que os prefeitos têm utilizado a escola pra dominar, pra ter cabos eleitorais, enfim, a escola tem sido instrumento de dominação de certos prefeitos nos assentamentos. E isso é uma contradição, porque a gente ocupa a terra, a conquista e dá os rumos pra muitas questões, mas quando chega na escola é reproduzida as relações capitalistas, que queremos negar (Membro do MST).

Percebemos que a proposta da escola da Educação do Campo, muito dialoga com a proposta da escola unitária pensada por Antônio Gramsci. 
Nesse sentido, aparece como um desafio para o MST, um aprofundamento contextualizado das ideias de Gramsci, tendo em vista que a escola unitária [...] deveria se propor a tarefa de inserir os jovens na atividade social, depois de tê-los levado a um certo grau de maturidade e capacidade, à criação intelectual e prática e a uma certa autonomia na orientação e na iniciativa [...] a inteira função de educação e formação das novas gerações torna-se, ao invés de privada, pública, pois somente assim pode ela envolver todas as gerações, sem divisões de grupos ou castas (GRAMSCI, 1988).

Entende-se por “escola do campo" (antagônica a idéia, já enraizada, de escola rural) aquela que trabalha desde os interesses, a política, a cultura e a economia dos diversos grupos de trabalhadores e trabalhadoras do campo, nas suas diversas formas de trabalho e de organização, na sua dimensão de permanente processo, produzindo valores, conhecimentos e tecnologias na perspectiva do desenvolvimento social e econômico igualitário dessa população. A identificação política e a inserção geográfica na própria realidade cultural do campo são condições fundamentais de sua implantação (Caderno Por uma educação básica do campo V. I)

Porém, esses desafios, assim como tantos outros, devem ser observados levando em consideração os limites e as possibilidades de materialização dessa proposta educacional. Com dois anos de experiência como bolsista do Projeto de Escolarização de Trabalhadores Rurais do PRONERA - UECE, fazendo o acompanhamento político-pedagógico de onze salas de aula de Educação de Jovens e Adultos, entre os anos de 2006 e 2008, pude observar as inúmeras dificuldades e contradições na concretização da Educação do Campo.

\section{Considerações finais: alguns desafios}

Apesar das dificuldades, intrínsecas ao desenvolvimento de qualquer projeto educacional que se proponha contribuir com a construção de uma nova hegemonia, as experiências e avanços construídos coletivamente têm mostrado que é possível a efetivação de projetos e iniciativas educacionais que considerem as experiências dos movimentos sociais camponeses, tendo 
a participação direta desses em suas formulações, planejamentos e execuções. Neste sentido, a Educação do Campo, talvez possa ser considerada uma das realizações práticas da pedagogia do oprimido e uma prova viva da atualidade da pedagogia socialista, à medida que afirma os camponeses como sujeitos legítimos de um projeto emancipatório.

No estado do Ceará, assim como em todo o país, o MST, com todos os limites e dificuldades, tem conseguido avançar consideravelmente nas elaborações teóricas e práticas (formais e informais) relacionadas à Educação do Campo.

É explícita, como se pôde observar, a partir da intencionalidade político-pedagógica dos projetos educacionais desenvolvidos, a necessidade (e prioridade) em se forjar intelectuais orgânicos do próprio Movimento, para contribuírem em um avanço qualitativo na luta pela terra. Assim a preocupação de Gramsci em se formar os intelectuais orgânicos da própria classe trabalhadora continua bastante pertinente. Segundo o autor italiano:

O modo de ser do novo intelectual não pode mais constituir na eloqüência, motor exterior e momentâneo dos afetos e das paixões, mas num imiscuir-se ativamente na vida prática, como construtor, organizador, "persuasor permanente" (GRAMSCI, 1988. p. 8)

Outro aspecto percebido no desenvolvimento da pesquisa, foi a íntima relação entre Educação do Campo e Educação Popular presente nos apontamentos do membro do MST, como podemos observar:

De fato, dizemos sim que trabalhamos com educação popular, inclusive a própria existência do Movimento está dentro dessa discussão, porque ela surge nesse anseio de utilizar a educação para servir como instrumento de emancipação da classe trabalhadora, de transformação da sociedade. Nós temos trabalhado com o teórico principal dessa questão que é Paulo Freire, infelizmente ele tem sido até distorcido pelo sistema educacional, onde se apropriam apenas da técnica que Paulo Freire utilizou para alfabetizar, abandonando sua filosofia. Pegam Paulo Freire e acabam distorcendo, fazendo uma educação bancária, que foi o que ele mais criticou (Membro do MST).

A apropriação de Freire pelo sistema de ensino oficial, segundo o 
interlocutor, enfatiza apenas a técnica de alfabetização "pura e simples", esvaziando-a de conteúdo político e filosófico. É oportuna a colocação de Leher (2005), quando sinaliza que autores ainda lidos hoje, como Vygostsky e Freire, o foram geralmente, em uma perspectiva estritamente pedagógica, desvinculada da política e das lutas anticapitalistas, quase que separada da sociedade de classes. Poderíamos, com toda tranqüilidade, incluir Antônio Gramsci nessa seleção de pensadores em que as apropriações de suas elaborações são feitas geralmente sem levar consideração sua totalidade, muito menos sua perspectiva revolucionária.

A partir dom estudo realizado, mesmo não pretendendo oferecer conclusões definitivas acerca da temática, pode-se levantar algumas considerações que acreditamos serem validas à Educação do Campo no atual momento:

1. É necessária a superação da dicotomia entre educação formal e informal no desenvolvimento da Educação do Campo. O PRONERA parece ser a principal referência;

2. A escola deve estar no centro da discussão da Educação do Campo, estabelecendo novos paradigmas para o sistema formal de ensino;

3. Os processos de formação continuada dos educadores e educadoras do campo devem proporcionar uma conexão entre teoria e prática desde a dinâmica escolar e do cotidiano dos trabalhadores(as) rurais;

4. Não se pode perder de vista a relação dialética entre as experiências educativas e as lutas das classes subalternas do campo;

5. É urgente o aprofundar do estudo das obras de Paulo Freire e o acúmulo teórico construído pela pedagogia socialista, a partir do legado de pensadores como Makarenko, Gramsci e Pistrak.

Portanto, só é possível a constituição de um processo, ou mesmo, um sistema educativo formal e/ou informal que contribua concretamente para um processo de emancipação das classes subalternas, se este tiver como horizonte a construção de uma nova sociedade, uma nova hegemonia.

A atual forma de sociabilidade, por implicar a exploração do homem 
pelo homem e a conseqüente desigualdade e exploração social, não pode permitir uma formação humana integral e emancipatória. Isto porque, esta formação exige o acesso aos bens materiais e espirituais necessários à plena realização dos indivíduos. Caso contrário, mesmo que progressistas e bem intencionadas, as iniciativas educacionais orientadas por qualquer paradigma crítico, acabarão reproduzindo a ideologia dominante, contribuindo com o agravamento da crise contemporânea na qual passa a humanidade.

\section{Referências bibliográficas}

CALDART, Roseli Salete. Pedagogia do Movimento Sem Terra. São Paulo: Expressão Popular, 2004.

CARVALHO, Sandra Maria Gadelha de. Educação na reforma agrária: pronera, uma politica pública? Tese de doutorado. Fortaleza: UFC, 2006.

Dossiê MST Escola: documentos e estudos 1990 - 2001. São Paulo: Expressão Popular, 2005.

FREIRE, Paulo. Pedagogia do Oprimido. São Paulo: Paz e Terra, 2005.

GRAMSCI, Antonio. Os intelectuais e a organização da cultura. Rio de Janeiro: Civilização Brasileira, 1988.

Jornal Sem Terra. Ano XXVII - Número 294. Julho de 2009.

KOLLING, Edgar Jorge; NERY, Ir; MOLINA, Mônica Castangna (Orgs). $A$ educação básica e o movimento social do campo - por uma educação básica do campo. Brasília: Editora Universidade de Brasília, 1999.

LEHER, Roberto. Educaşão popular como estratégia politica. In JEZINE, Edineli; ALMEIDA, Maria de Lourdes (Orgs). Educação e movimentos sociais: novos olhares. Campinas - São Paulo: Alínea, 2007.

NOSELLA, Paolo. A escola de Gramsci. São Paulo: Cortez, 2004.

PORTELLI, Hugues. Gramsci e o bloco histórico. Rio de Janeiro: Paz e Terra, 2002.

SAVIANI, Dermeval. Escola e democracia: teorias da educação, curvatura da vara, onže teses sobre educação e política. São Paulo: Cortez: Autores Associados, 1989. 